\title{
PERSONALIDADE DA MARCA, SIGNIFICADO DO PRODUTO E IMPULSIVIDADE NA COMPRA POR IMPULSO: um estudo em ambiente de shopping center
}

\section{1-Marconi Freitas da Costa*}

Doutor em Administração pelo Universidade Federal de Pernambuco (PROPAD/UFPE), Brasil.

Professor Adjunto do Núcleo de Gestão da Universidade Federal de Pernambuco (UFPE), Campus Caruaru, Brasil. marconi_costa@hotmail.com

http://lattes.cnpq.br/7359522003689133

\section{2-Thaísa da Silva Paula}

Mestre em Engenharia de Produção pela Universidade Federal de Pernambuco (UFPE), Campus Caruaru, Brasil. thaisa_paula15@hotmail.com

http://lattes.cnpq.br/8082609643977771

\section{3-Claudio Felisoni de Angelo}

Doutor em Economia pela Universidade de São Paulo (FEA/USP), Brasil

Professor do programa de Pós-Graduação em Administração da Universidade de São Paulo (PPGA/FEA-USP).

cfa@usp.br

http://lattes.cnpq.br/8271076610806341

\section{4-Nuno Manoel Martins Dias Fouto}

Doutor em Administração pela Universidade de São Paulo (FEA/USP), Brasil.

Professor do programa de Pós-Graduação em Administração da Universidade de São Paulo (PPGA/FEA-USP), Brasil. nfouto@usp.br

http://lattes.cnpq.br/8895730550207418

\author{
Diego Maganhotto Coraiola - Editor Geral \\ Editor responsável pela submissão: \\ Diego Maganhotto Coraiola. \\ Artigo analisado via processo de revisão duplo cego (Double-blind). \\ Recebido em: 27/04/2017 \\ Aprovado em: 16/05/2017 \\ Última Alteração: 20/08/2017
}

* Contato Principal: Rodovia BR-104, Km 59, s/n - Nova Caruaru, Caruaru - PE, CEP: 55002-970 
PERSONALIDADE DA MARCA, SIGNIFICADO DO PRODUTO E IMPULSIVIDADE NA COMPRA POR IMPULSO: UM ESTUDO EM AMBIENTE DE SHOPPING CENTER

\title{
RESUMO
}

O presente estudo tem como objetivo analisar a influência dos construtos significado do produto, personalidade da marca e impulsividade na compra por impulso no ambiente de shopping center. A pesquisa busca explicar o comportamento de compra por impulso levando em consideração a importância da impulsividade do indivíduo como fator de significativa influência na compra por impulso e trazer como contribuição a inclusão de dois construtos que até então não foram explorados conjuntamente nos estudos de compra por impulso: significado do produto e personalidade da marca. Foi feita uma pesquisa descritiva e correlacional, com abordagem de natureza quantitativa. A amostra é composta por 317 respondentes. Os resultados permitiram ratificar que os indivíduos mais impulsivos tendem a fazer, com maior frequência, compras por impulsos, ou seja, apresentam dificuldade em controlar seus impulsos de compra. Como contribuição da presente pesquisa tem-se que os produtos adquiridos de forma impulsiva são aqueles compatíveis com a imagem dos consumidores, que refletem quem eles são. Os participantes afirmaram que eram atribuídas personalidades aos produtos comprados impulsivamente. Quanto mais essa personalidade da marca conseguia identificar-se com o consumidor e o seu estilo de vida, mais os produtos estariam propensos a serem adquiridos impulsivamente.

Palavras-chave

Compra por impulso; Impulsividade; Personalidade da marca; Significado do produto; Shopping Center.

\section{BRAND PERSONALITY, PRODUCT MEANING AND IMPULSIVENESS WHEN BUYING: A STUDY IN A SHOPPING CENTER ENVIRONMENT}

\begin{abstract}
This study aims to analyze the influence of product meaning, brand personality and impulsiveness when buying in the mall environment. The research seeks to explain impulse buying taking into account the importance of the individual impulsivity as a significant factor influence on impulse buying and bring a contribution to the inclusion of two theories that hitherto have not been explored jointly in studies of impulse buying: product meaning and brand personality. A descriptive and correlational research was done with quantitative approach. The sample is composed of 317 respondents. The results allowed us to confirm that individuals who are more impulsive tend to make impulse purchases more frequently, that is, they have difficulty controlling their buying impulses. In addition, and as a contribution to this research, products purchased impulsively are those compatible with the image of consumers that reflect who they are. The participants noted that they were attributed personalities to products purchased impulsively. The more the brand personality can identify with the consumer and his lifestyle, more products would be likely to be purchased impulsively.
\end{abstract}

\section{Keywords}

Impulse buying; Impulsiveness; Brand personality; Product meaning; Shopping Center. 
Personalidade da marca, significado do produto e impulsividade na compra por impulso: um estudo em ambiente de shopping center

\section{Introdução}

A sociedade de consumo, termo utilizado por Baudrillard (2005), parece criar a necessidade de "consumir" o valor simbólico atribuído tanto aos produtos como aos serviços oferecidos. O consumo de mercadorias é cada vez mais estimulado na sociedade, uma vez que não se realiza somente pela compra de bens, mas também por meio da aquisição de valores simbólicos que acompanham o produto adquirido (Darrat, Darrat \& Amyx, 2016).

Como afirmam Douglas e Isherwood (2009), este sentido de consumo como algo biologicamente necessário, naturalmente inscrito e universalmente experimentado está em um plano completamente diferente do dilema com que a cultura contemporânea defronta ao se escolher marcas de carros, sabores de refrigerante, lojas de departamentos, estilos de roupas, telefones celulares, serviços bancários, restaurantes, geladeiras, manteigas ou batons. É neste plano que o consumo se torna uma questão cultural, simbólica (Huang, 2016).

Nos dias atuais, o simbolismo contido em um produto interfere na decisão de compra tanto ou até mais do que as características funcionais (Ozer \& Gultekin, 2015). Como exemplo, Santarelli (2003) afirma que a compra de uma peça de roupa não é voltada apenas à satisfação de uma utilidade prática ou para proteção: envolve também o tipo do tecido, o conforto, o sexo do usuário da roupa, a aceitação daquela peça por parte do grupo social no qual se está inserido e toda uma série de variáveis.

Todos os bens têm aspectos simbólicos, e o comportamento de consumo é influenciado implícita ou explicitamente por esse simbolismo (Levy, 1959). A cultura do consumo, contexto no qual está inserida a compra por impulso, "tem notória afinidade com signos, imagens, publicidade" (Slater, 2001, p. 38). E o valor simbólico atribuído ao produto favorece a compra por impulso (Babin, Darden \& Griffin, 1994; Amos, Holmes \& Keneson, 2014).

A compra por impulso vem sendo estudada desde o início dos anos 1950. Nos anos 1960, o termo compra por impulso era sinônimo de compra não planejada. Para Arnould, Price e Zinkhan (2004), "a compra por impulso ocorre quando consumidores sentem um desejo repentino, sempre forte, e um desejo emocional persistente de comprar imediatamente" (p. 678). A compra por impulso é resultado de influências ambientais e fatores psicodinâmicos internos (Youn \& Faber, 2000). Para compreender o comportamento de compra por impulso, devese entender a questão da impulsividade, que é a tendência em responder rapidamente e sem reflexo (Dholakia, 2000). Os indivíduos impulsivos enfrentam dificuldade em controlar suas reações e por não terem objetivos nem regras em suas atividades de consumo, apresentam maior tendência em comprar impulsivamente (Baumeister, 2002; Ozer \& Gultekin, 2015).

Diante do exposto pode-se perceber que o estudo do comportamento do consumidor tem evoluído de uma análise com foco no comportamento do consumidor para uma abordagem do consumo. O comportamento de consumo é altamente influenciado por elementos distantes dos aspectos funcionais, e o consumidor leva em consideração aspectos simbólicos e relacionados com a sua própria imagem (Xiang, Zheng, Lee \& Zao, 2016). Existe, portanto, uma ligação visível entre a imagem do usuário com a imagem de produtos e marcas que ele consome (Muniz \& Marchetti, 2005). Dessa forma, a marca ganhou destaque como um elemento diferenciador e cuja avaliação do consumidor ultrapassa os aspectos racionais e funcionais. Um produto idêntico pode ser avaliado de maneira diferente, dependendo da identificação ou atribuição de marca que lhe é dada (HemsleyBrown, Melewar, Nguyen \& Wilson, 2016).

As marcas fortes são vistas como um diferencial competitivo. Segundo Aaker e Biel (1993), um esforço substancial de pesquisa tem sido canalizado para definir, medir e entender os antecedentes e consequentes da construção de marcas fortes. Há uma necessidade de compreender as facetas que as marcas representam ou desejam refletir para os consumidores e, dentre elas, está a personalidade da marca, um atributo intangível. Aaker (1997) define personalidade de marca como um "conjunto de características humanas associadas a uma marca" (p. 347).

Muitos autores realizaram debates e ensaios a respeito da personalidade de marca (Aaker, 1997; Aaker \& Biel, 1993; Ranfagni, Camiciottoli \& Faraoni, 2016), procurando conceituá-la, discutindo formas de medi-la e estimando as implicações desse construto para o comportamento do consumidor. Questionaram se os produtos e marcas poderiam ter uma personalidade, e se estas marcas, por possuírem tal dimensão, poderiam evocar sentimentos, emoções e comportamentos assim como os seres humanos (Caprara, Barbaranelli \& Guido, 1998). De acordo com essa personalidade os consumidores decidem se a marca o representa ou não. 
O significado que um consumidor atribui a um produto serve como base importante para compreender seu comportamento de compra (Nepomuceno \& Torres, 2005). Segundo Das (2014) a compra por impulso está associada à relação existente entre o significado do produto e a autoimagem desejada no indivíduo. A busca por objetos e relacionamentos que simbolizam ou caracterizam o estado ideal ou desejado leva o indivíduo a engajar-se em comportamentos impulsivos de compra, quando é percebida a compatibilidade entre o objeto (produto) e sua autoimagem desejada (Belk, 1988).

Enquanto seres humanos, nossas vidas se traduzem na criação de uma existência simbólica. 0 consumo não foge à regra: não pode ser definido materialmente em termos de desejos ou necessidades, mas a partir de uma série de significados que fazem com que as pessoas se sintam atraídas a consumir, o que não significa, em última instância, uma compra material. O ambiente de shopping centeré, por excelência, um espaço carregado do universo simbólico próprio do consumo. Ele consegue agregar uma gama variada de produtos e serviços em um único espaço, também consegue, pelo lado do consumo, representar um tipo de sociabilidade capaz de atrair até mesmo, em certos contextos, pessoas sem dinheiro (Amos, Holmes \& Keneson, 2014).

Os consumidores são cada vez mais influenciados a comprar. E o ambiente dos shoppings centers pode ser visto como uma armadilha para capturar compradores em potencial (Tegglen, 1979; Padilha, 2006). Segundo Underhill (2009) estes ambientes são capazes de preencher as necessidades e anseios dos consumidores.

O crescimento do comércio em shoppings centers impacta no comportamento de consumo e na necessidade de conhecer mais sobre os fatores que afetam o comportamento da compra por impulso. Considerando-se, então, a relevância dos construtos abordados por esta pesquisa na compra por impulso, traçou-se o seguinte objetivo geral: analisar a influência dos construtos significado do produto, personalidade da marca e impulsividade do indivíduo na compra por impulso, que por sua vez desdobrou-se nos seguintes objetivos específicos: (a) analisar o impacto da impulsividade do indivíduo na ocorrência de compras por impulso; (b) avaliar a importância da personalidade da marca na escolha de um produto e consequentemente a sua compra por impulso; e (c) analisar a influência que o significado do produto exerce sobre a compra por impulso.

\subsection{Justificativa do Estudo}

O conhecimento sobre a compra por impulso ainda carece de um entendimento mais aprofundado. O tema apresenta-se em um estágio imaturo se comparado com outras áreas das ciências do consumo (Amos, Holmes \& Keneson, 2014). Conforme notado por Dholakia (2000) a compra por impulso tem recebido pouca atenção dos pesquisadores, portanto, o presente estudo visa contribuir, por meio da exploração dos construtos significado do produto, personalidade da marca e impulsividade do indivíduo na compra por impulso, para o avanço do conhecimento nesta área tanto na teoria como na prática. Ao aproximar o modelo acadêmico à realidade empresarial pretende-se ampliar a base para a tomada de decisões estratégicas, bem como apresentar para as organizações um diferencial competitivo.

Como a competição tem se intensificado, é importante que os profissionais estejam cientes da real dimensão da importância da marca, visto que ela ganhou destaque como um elemento diferenciador. Dessa forma, é preciso compreender que a marca possui uma representatividade importante no processo de decisão de compra.

Estudos até então desenvolvidos não contemplaram a influência da marca (e.g., Aaker, 1997; Caprara, Barbanelli \& Guido, 1998; Das, 2014) e do significado do produto (e.g., Richins, 1994; Allen, 2000; Ranfagni, Camiciottoli \& Faraoni, 2016) conjuntamente, na compra por impulso. Assim sendo, apresenta-se uma importante oportunidade de estudo para melhor compreensão desse fenômeno. Portanto, a busca por modelos que expliquem o comportamento de compra por impulso é recente e requerem questionamentos, aperfeiçoamentos e validações empíricas (Costa, 2002).

Visto que o ambiente dos shoppings centers, segundo uma visão crítica ao consumismo (Padilha, 2006; Tegglen, 1979), pode ser visto como uma armadilha para capturar compradores em potencial e tendo em vista a carência de estudos reportando os fatores que influenciam a compra por impulso neste tipo de ambiente, este estudo deseja contribuir no avanço do conhecimento nessa área.

Por fim, esta pesquisa buscou investigar se os construtos da personalidade da marca e do significado do produto, em conjunto com a impulsividade do indivíduo, teriam uma contribuição para um melhor entendimento das decisões de compra por impulso. Acredita-se na relação desses construtos com a compra por impulso porque quando o indivíduo percebe uma compatibilidade 
Personalidade da marca, significado do produto e impulsividade na compra por impulso: um estudo em ambiente de shopping center

entre o objeto e sua autoimagem, este se engaja em comportamentos impulsivos (Belk, 1988; Dittmar, Beattie \& Friese, 1995).

\section{Revisão da Literatura}

\subsection{Impulsividade e Compra por Impulso}

Para compreender o comportamento de compra por impulso, deve-se entender a questão da impulsividade do consumidor. Dholakia (2000) define impulsividade como a tendência de responder rapidamente e sem reflexão. Para Rook (1987), um impulso não é conscientemente planejado, mas emerge imediatamente quando confrontado com certos estímulos bioquímicos e psicológicos. Assumida como um traço de personalidade humana, a inclinação da pessoa em agir sem deliberação ou reflexão sobre as consequências de suas decisões é uma condição para que ocorra a compra por impulso.

Para Hoch e Loewenstein (1991), a impulsividade é decorrente do conflito psicológico entre o autocontrole e os desejos do indivíduo. Segundo Youn (2000), a impulsividade do consumidor está fortemente associada à emoção. Diante disso, acredita-se que os consumidores impulsivos tendem a encarar a atividade de compra como um tipo de lazer, sua realização pode trazer sentimentos favoráveis e positivos (Costa \& Farias, 2016).

Quando analisada do ponto de vista do consumo, a compra por impulso tem sido relacionada com consequências negativas como inadimplência e arrependimento pós-compra. Esta situação está relacionada com a compulsividade do consumidor. De acordo com Nohara, Acevedo e Nogueira Neto (2015) a compra de produtos desnecessários não é racional e, em muitas situações, o consumidor compulsivo esconde a compra e ultrapassa os limites orçamentários, levando a sérias consequências sociais e pessoais. Para o consumidor compulsivo o sentimento que prevalece é o remorso pela compra (O'Guinn \& Faber, 1989). Segundo Faber (1992) as compras excessivas foram caracterizadas como desordens mentais no início do século XX, por Kraepelin e também por Bleuler.

Os motivos que levam à compra por impulso, no entanto, podem ser positivos. Segundo Rook (1987) a impulsividade, muitas vezes, emerge de um ato de bondade como comprar um presente ou aproveitar uma promoção do tipo "leve dois e pague um". Segundo Baumeister (2002), os indivíduos impulsivos enfrentam dificuldade em controlar suas reações. Indivíduos esses que, sem objetivos nem regras em suas atividades de consumo, apresentam maior tendência a comprar impulsivamente em busca de uma recompensa imediata.

A cultura do consumo, contexto no qual está inserida a compra por impulso, "tem notória afinidade com signos, imagens, publicidade" (Slater, 2001, p. 38). O comportamento de consumo é altamente influenciado por elementos distantes dos aspectos funcionais, e o consumidor leva em consideração aspectos simbólicos e relacionados com a sua própria imagem. Esse valor simbólico atribuído ao produto favorece a compra por impulso (Babin, Darden \& Griffin, 1994). Existe, portanto, uma ligação perceptível entre a imagem do usuário com a imagem de produtos e marcas que ele consome (Muniz \& Marchetti, 2005). A partir do que foi exposto, estabeleceu-se a seguinte hipótese.

Hipótese 1: Quanto maior a impulsividade do indivíduo, maior será sua tendência a realizar compras por impulso.

\subsection{Personalidade da Marca}

A personalidade da marca é um conjunto de características humanas associadas a uma marca que reflete uma realidade mais rica e interessante do que aquela baseada nos atributos dos produtos (Aaker, 1997). Para Ranfagni, Camiciottoli e Faraoni (2016), a personalidade da marca trata-se de uma combinação de características humanas que podem ser associadas a uma marca específica. Assim, os consumidores tendem a escolher a marca que melhor se adapte à sua personalidade (Sundar \& Noseworthy, 2016). Kapferer (2004), por sua vez, afirma que a personalidade da marca é conhecida de acordo com seus discurso e comportamento, mostrando que tipo de pessoa ela seria. A partir do momento em que a marca começa a se comunicar com seu público, ela vai adquirindo um caráter que, com o passar do tempo, forma a sua personalidade (Ranfagni, Camiciottoli \& Faraoni, 2016).

Caprara, Barbaranelli e Guido (1998) sugerem que a personalidade como uma metáfora da marca pode seguir um procedimento semelhante ao procedimento realizado com a personalidade 
humana para distinguir dimensões com alto poder e descrição e acumulação dos demais traços. Estudos posteriores mostraram que a simples transposição da escala da personalidade humana para as marcas não se mostra adequada, fazendo-se necessário algumas modificações (Ferguson, Lau \& Phau, 2016).

Aaker (1997) conseguiu estabelecer um quadro teórico do construto personalidade de marca. Segundo a autora, a personalidade de marca é descrita em cinco dimensões: Sinceridade, Agitação, Competência, Sofisticação e Robustez. Nesse quadro é determinado o número de dimensões que compõem a personalidade da marca, descrevendo-as como um conjunto de traços de personalidade (Eisend \& Stokburger-Sauer, 2013). Dessa forma, uma escala de medidas confiável, válida e generalizável foi criada no contexto americano, facilitando o aprofundamento em outras questões relativas à personalidade de marca.

Existe a necessidade de se testar e/ou desenvolver escalas para o entendimento do uso simbólico das marcas em outros contextos, entre diferentes culturas (Aaker, 1997). Embora as dimensões da personalidade humana mostrem robustez quando aplicadas em outras culturas, o mesmo não pode ser dito para a personalidade de marca (Grohmann, Giese \& Parkman, 2013). A escala de Aaker (1997) foi replicada ou reconstruída em outros estudos com diferentes contextos (Aaker, Benet-Martízez \& Garolera, 2001; Supphellen \& Gronhaug, 2003), apresentando algumas semelhanças e diferenças nas dimensões da personalidade da marca nos resultados encontrados.

Segundo Ferguson, Lau e Phau (2016) uma personalidade de marca consistente e aceita pode auxiliar na construção de uma marca sólida. Diante do exposto foi definida a seguinte hipótese:

Hipótese 2: Os consumidores que mais se identificam com a personalidade da marca tendem a comprar mais por impulso.

\subsection{Significado do Produto}

A cada evento, a cada objeto, a cada pertence, a cada pessoa e a cada palavra, as pessoas atribuem um significado. Segundo a semiótica (Allen, 2000), a decodificação do significado de um gesto pode ser essencial para compreender a reação ou o comportamento de um indivíduo. O significado que um consumidor atribui a um produto serve como base importante para compreender seu comportamento de compra (Brunner, Ullrich, Jungen \& Esch, 2016). Richins (1994) considera que o valor atribuído ao produto por um indivíduo é, na verdade, mais do que o seu valor monetário, ou seja, o seu valor simbólico. Assim, o significado de um produto é particular a cada pessoa (Thaler, 1985).

Outros autores (Belk, 1988; Dean; Arroyo-Gamez; Punjaisri \& Pich, 2016; Tamayo, 1981) ressaltam a relevância e influência que as posses geram no desenvolvimento da identidade e no autoconceito de um indivíduo. Tamayo (1981) resume o autoconceito como um conjunto de percepções de si mesmo. O conteúdo dessas percepções é tudo aquilo que o indivíduo reconhece como fazendo parte de si (Dean et al., 2016). McCracken (2003) sugere que as posses podem servir de instrumento para manter o autoconceito. Pode-se dizer que o significado atribuído a um produto ou serviço é o resultado das emoções ou sentimentos (componente afetivo) que a pessoa obteve a partir da experiência com o objeto (produto ou serviço).

O significado de um produto ainda pode ser o resultado da expressão de um valor, por meio da atribuição de significado de acordo com seus valores pessoais (Hemsley-Brown et al., 2016). Cinco categorias de significado foram sugeridas por Richins (1994): valor utilitário, de entretenimento, representante de laços interpessoais, identidade e auto-expressão. Essas categorias se aglutinam em duas categorias mais abrangentes, isto é, o significado utilitário e o simbólico (Allen, 2000; Nepomuceno \& Torres, 2005).

Segundo Dittmar, Beattie e Friese (1995) a compra por impulso está associada à relação existente entre o significado do produto e a autoimagem desejada no indivíduo. Produtos que podem simbolizar uma aproximação do estado atual do indivíduo a uma autoimagem ideal possuem maior tendência a ser adquiridos impulsivamente (Brunner et al., 2016). Entende-se como autoconceito e autoimagem a imagem que o indivíduo faz de si mesmo, compreendendo suas atitudes, crenças, valores, identidades e estados afetivos (Hemsley-Brown et al., 2016).

A busca por objetos e relacionamentos que simbolizam ou caracterizam o estado ideal ou desejado leva o indivíduo a engajar-se em comportamentos impulsivos de compra, quando é percebido a compatibilidade entre o objeto (produto) e sua autoimagem desejada (Belk, 1988). Por fim, foi estabelecida a terceira e última hipótese. 
Personalidade da marca, significado do produto e impulsividade na compra por impulso: um estudo em ambiente de shopping center

Hipótese 3: Quanto maior for a avaliação do consumidor quanto ao significado do produto, maior será a chance desse produto ser adquirido por impulso.

\section{Procedimentos Metodológicos}

\subsection{Delineamento da Pesquisa}

A pesquisa é de natureza quantitativa e, quanto aos fins, é descritiva e correlacional. Quanto aos meios, a pesquisa é de campo. A coleta de dados foi feita por meio de questionário estruturado (Malhotra, 2006).

\subsection{Participantes}

Este estudo tem como base uma amostra não probabilística, cuja população amostral constituiu-se de consumidores que realizam compras em determinado shopping center, junto aos quais foram aplicados 330 questionários. Após a eliminação de alguns instrumentos de coleta de dados por problemas no preenchimento, a amostra final foi de 317 questionários.

\subsection{Instrumento e Procedimento de Coleta}

O questionário de pesquisa foi elaborado a partir de indicadores de quatro trabalhos: para o construto da impulsividade foi utilizada a escala de Youn (2000) com 10 itens; para o construto da personalidade da marca foi emprega a escala de Aaker (1997) e adaptada para o contexto brasileiro por Muniz \& Marchetti (2005) com 11 itens; para o construto do significado do produto foi utilizada a escala de Nepomuceno \& Torres (2005) com 10 itens, tendo a inclusão de 3 novos itens, elaborados pelos autores deste artigo; e o construto da compra por impulso foi mensurado por apenas 1 item, elaborado por Beatty \& Ferrel (1998) e adaptado por Costa (2002) para o contexto brasileiro.

As escalas selecionadas para mensurar cada construto desse estudo são escalas amplamente utilizadas na área do comportamento do consumidor. Estas escalas apresentaram valores elevados de confiabilidade e validade nos estudos em que foram utilizadas. As escalas foram traduzidas do idioma original para o português por meio de tradução reversa. Alguns itens das escalas foram retirados ou contextualizados para o escopo desta pesquisa, após a realização do pré-teste, que será explicado mais adiante.

Com base nas escalas, foi montado um questionário contendo 35 questões, que os participantes responderam avaliando o quanto concordavam ou discordavam de cada item de acordo com uma escala tipo Likert (Malhotra, 2006). A escala construída, balanceada, variava de 1 a 7. 0 número 1 , indicando que a pessoa discordava totalmente e o número 7 , que indicava que a pessoa concordava totalmente.

Com a finalidade de avaliar o instrumento de coleta de dados foi aplicado um teste-piloto. Foram realizadas 20 abordagens com potenciais respondentes. Algumas considerações foram observadas: o tempo médio para responder o questionário foi de 4 minutos. Não foram recebidas críticas ao instrumento de coleta ou encontrada dificuldade no seu preenchimento. Com os dados coletados foram feitos alguns testes estatísticos, por exemplo, análise fatorial, para analisar preliminarmente o instrumento de coleta de dados, além da avaliação qualitativa.

Os respondentes foram abordados no momento em que saiam das lojas, por terem acabado de vivenciar a experiência de compra. A coleta foi realizada entre os dias 20 e 21 de agosto de 2013 no horário de $14 \mathrm{~h}$ às $22 \mathrm{~h}$.

\subsection{Procedimentos de Análise}

Após a avaliação do pré-teste, com os dados da coleta definitiva, os dados foram analisados por meio de frequência, média e desvio-padrão. Para testar as hipóteses propostas neste estudo, foi utilizada a Análise da Variância (ANOVA), a fim de analisar a variância de um fator e verificar as diferenças entre médias de subgrupos. Para determinar quais variáveis impactam significativamente na compra por impulso utilizou-se a análise de regressão logística. Para isso, tinha-se a variável dependente compra por impulso. 


\section{Apresentação e Análise dos Resultados}

Inicialmente foi analisado o perfil do respondente. A amostra se revelou equilibrada quanto ao número de homens e mulheres, tendo, entretanto, um número um pouco maior de homens, com $51,7 \%$. Em relação à idade, 33,4\% dos respondentes estavam na faixa entre 16 a 20 anos, 28,1\% entre 21 a 25 anos, 23,7\% entre 26 a 30 anos, 5\% entre 31 a 35 anos e, por fim, 9,8\% acima dos 35 anos. O público até 30 anos representou $85,2 \%$ dos respondentes. Quanto ao estado civil 74,4\% dos respondentes eram solteiros e $25,6 \%$ casados. De acordo com os dados percebe-se que $1,6 \%$ declararam renda até $R \$ 678,00,77,3 \%$ entre $R \$ 679,00$ a $2.034,00$ e $21,1 \%$ percebiam acima de $R \$$ 2.034,00.

\subsection{Análise da Dimensionalidade e Confiabilidade dos Construtos}

Para analisar a dimensionalidade das escalas foi utilizada a Análise Fatorial Exploratória (AFE). Para verificar o construto impulsividade do consumidor foi utilizada uma escala de concordância sete pontos com 10 itens. Por meio da AFE constatou-se a aceitabilidade da escala, visto que a variância explicada foi $71,20 \%$, de acordo com Hair, Babin, Money \& Samoul (2005), variância acima de $50 \%$ é aceitável. Da análise emergiu um fator, com a exclusão de quatro itens, todos com cargas fatoriais elevadas (Tabela 1 ).

Para verificar o construto personalidade da marca foi utilizada uma escala de concordância de sete pontos e onze itens. Foram gerados dois fatores, com a exclusão de dois itens que apresentavam baixas cargas fatoriais, os demais itens compuseram apenas um fator, com uma variância explicada aceitável de 63,34\%.

Tabela 1

Estatísticas dos construtos

\begin{tabular}{|c|c|c|c|c|c|c|}
\hline & \multirow{2}{*}{ Itens } & \multirow{2}{*}{ KMO } & \multicolumn{2}{|c|}{$\begin{array}{l}\text { Esfericidade } \\
\text { de Bartlett }\end{array}$} & \multirow{2}{*}{ Fator } & \multirow{2}{*}{ Cronbach } \\
\hline & & & $x^{2}$ & $P$ & & \\
\hline \multirow[t]{10}{*}{$\begin{array}{l}\text { Impulsividade } \\
\text { Youn (2000) }\end{array}$} & $\begin{array}{l}\text { Tenho dificuldade para controlar meus } \\
\text { impulsos de compra. }\end{array}$ & \multirow{10}{*}{0,892} & \multirow{10}{*}{1368,396} & \multirow{10}{*}{0,000} & 0,899 & \multirow{6}{*}{0,917} \\
\hline & $\begin{array}{l}\text { A necessidade de comprar algo surge de } \\
\text { repente e me surpreendo. }\end{array}$ & & & & 0,882 & \\
\hline & $\begin{array}{l}\text { Frequentemente, compro produtos que } \\
\text { não necessito. }\end{array}$ & & & & 0,889 & \\
\hline & $\begin{array}{l}\text { Sou uma pessoa que faz compra não } \\
\text { planejada. }\end{array}$ & & & & 0,864 & \\
\hline & $\begin{array}{l}\text { Quando faço compras por impulso, me } \\
\text { divirto e fico entusiasmado(a). }\end{array}$ & & & & 0,756 & \\
\hline & $\begin{array}{l}\text { Quando estou deprimido(a), saio e } \\
\text { compro algo impulsivamente. }\end{array}$ & & & & 0,760 & \\
\hline & Sou um(a) consumidor(a) cauteloso(a). & & & & & Excluído \\
\hline & $\begin{array}{l}\text { Geralmente penso em opções de } \\
\text { produtos para fazer um bom negócio. }\end{array}$ & & & & & Excluído \\
\hline & $\begin{array}{l}\text { Mesmo quando vejo um produto } \\
\text { atraente, penso nas consequências da } \\
\text { sua compra. }\end{array}$ & & & & & Excluído \\
\hline & $\begin{array}{l}\text { Comprar é uma forma de reduzir o } \\
\text { estresse da vida. }\end{array}$ & & & & & Excluído \\
\hline \multirow{11}{*}{$\begin{array}{c}\text { Personalidade } \\
\text { da Marca } \\
\text { Aaker (1997) e } \\
\text { Muniz \& } \\
\text { Marchetti } \\
\text { (2005) }\end{array}$} & Diversão & \multirow{11}{*}{0,686} & \multirow{11}{*}{1985,652} & \multirow{11}{*}{0,000} & 0,656 & \multirow{9}{*}{0,865} \\
\hline & Informalidade & & & & 0,609 & \\
\hline & Ousadia & & & & 0,700 & \\
\hline & Modernidade & & & & 0,746 & \\
\hline & Juventude & & & & 0,725 & \\
\hline & Elegância & & & & 0,735 & \\
\hline & Glamour & & & & 0,645 & \\
\hline & Sensibilidade & & & & 0,724 & \\
\hline & Emoção & & & & 0,705 & \\
\hline & Confiança & & & & & Excluído \\
\hline & Responsabilidade & & & & & Excluído \\
\hline
\end{tabular}


Personalidade da marca, significado do produto e impulsividade na compra por impulso: um estudo em ambiente de shopping center

Continuação...

\section{Significado do Produto} Nepomuceno \& Torres (2005) e Autores deste artigo (2013)
A imagem que um produto possui é uma parte importante da minha decisão de comprá-lo.

Prefiro produtos que estão na moda.

Gosto de produtos que são reconhecidos como caros.

Geralmente compro por impulso produtos que são compatíveis com a minha imagem.*

Normalmente, seleciono um produto baseado em um sentimento ou impulso interno.

Prefiro produtos de marcas conhecidas e fortes.*

Geralmente faço compras por impulso, quando me deparo com um produto que reflete quem eu sou.*

Eu acredito ser lógico(a) e racional quando decido sobre um produto.

Antes de tomar a decisão final por um produto penso nos prós e contras sobre o mesmo.

Antes de tomar a decisão final por um produto penso em mim como usuário(a).

Eu acredito em exercitar o autocontrole e não ser impulsivo(a) na escolha do produto.

Eu prefiro um produto que reflete quem eu sou.

Quando estou decidindo pela compra de um produto, penso na utilidade dele.

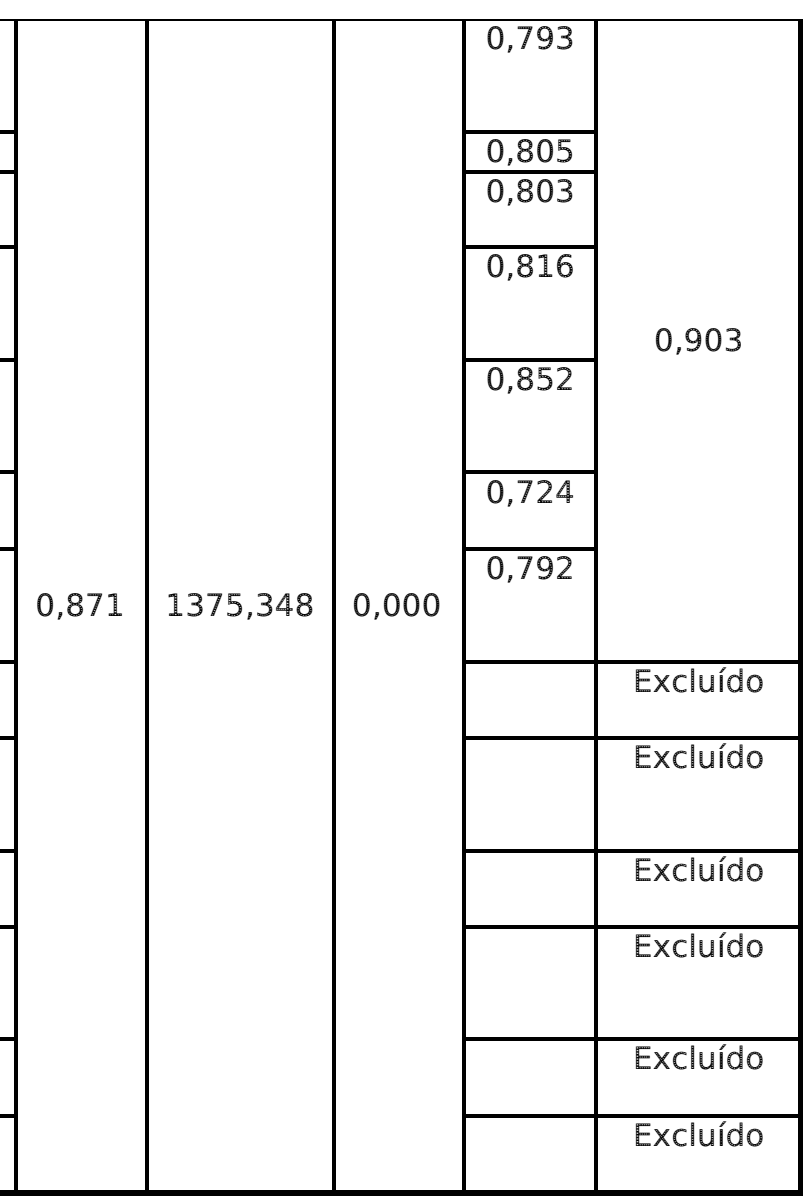

Nota.* Itens criados pelos autores deste artigo. Fonte: Elaborado pelos autores.

A escala de significado do produto também apresenta uma escala balanceada de concordância-discordância, do tipo Likert de sete pontos e treze itens. A análise fatorial gerou um fator, que obteve uma variância explicada aceitável de 63,78\%. Seis itens foram excluídos. Os itens que foram excluídos da escala do significado do produto tinham uma característica mais racional, prevalecendo às características simbólicas. Assim, será adotado nesse artigo o termo de significado simbólico do produto após essa análise. A compra por impulso foi mensurada por apenas um item: "Geralmente compro produtos que não tinha intenções de adquirir antes de entrar na loja", também com uma escala de concordância do tipo Likert, de sete pontos.

As cargas fatoriais dos itens de todos os construtos são consideradas elevadas - a menor foi 0,609 , assim como os valores de alfa de Cronbach cujo menor resultado foi 0,865 , de acordo com parâmetros indicados por Hair et al. (2005).

\subsection{Testes das Hipóteses}

No presente estudo foi utilizada a Análise da Variância (ANOVA). Foram criados três subgrupos para o construto impulsividade: baixa impulsividade, moderada impulsividade e alta impulsividade. Para avaliar a hipótese de que quanto maior a impulsividade do indivíduo maior será sua tendência a realizar compras por impulso, foi feito o teste de hipótese da ANOVA one way e o resultado apresenta significância estatística $(F(314,2)=135,539 ; p=0,000)$, permitindo que se rejeite $\mathrm{H}_{0}$. Com isso, aceita-se a hipótese.

Os dados demonstraram o que alguns autores já haviam mencionado (Baumeister, 2002; Rook \& Hoch, 1985): os indivíduos impulsivos enfrentam dificuldade em controlar seus impulsos de compra e, por não possuírem objetivos e nem regras em suas atividades de consumo, apresentam maior tendência a comprar impulsivamente. Desta forma, a hipótese $\mathrm{H}_{1}$ está em concordância com a teoria existente sobre impulsividade do consumidor. Portanto, o construto impulsividade contribui de forma significativa para a realização de compras por impulso. 
No presente estudo buscou-se, também, analisar a influência da personalidade da marca na compra por impulso $\left(\mathrm{H}_{2}\right)$. O construto personalidade da marca foi dividido em três subgrupos: baixa personalidade da marca, moderada personalidade da marca e alta personalidade da marca. Desse modo, objetivou-se testar a hipótese: os consumidores que mais se identificam com a personalidade da marca tendem a comprar mais por impulso. O teste mostrou que $(F(314,2)=6,615 ; p=0,002)$ há uma diferença entre as médias dos subgrupos, com alta personalidade recebendo uma avaliação maior na escala. Isto deixa evidente que quanto mais o consumidor se identificar com a personalidade da marca, maior será sua tendência em realizar compras por impulso. O construto encontra-se relacionado com a variável dependente compra por impulso.

A confirmação dessa hipótese $\left(\mathrm{H}_{2}\right)$ corrobora para o que muitos autores afirmam (Levy, 1959; Aaker, 1997; Muniz \& Marchetti, 2005) que o uso simbólico das marcas é possível porque os consumidores impregnam a marca com traços humanos de personalidade. A marca que consegue se identificar com o estilo de vida do consumidor está mais propensa a ser adquirida por impulso. As pessoas compram as coisas influenciadas pelos aspectos simbólicos, associado ao que essas coisas significam ou querem dizer.

Por fim, foi testada a última hipótese formulada $\left(\mathrm{H}_{3}\right)$ : quanto maior for a avaliação atribuída pelo consumidor ao significado simbólico do produto, maior será a chance desse produto ser adquirido por impulso. Assim como os outros construtos analisados, o significado simbólico do produto foi divido em três subgrupos: baixo significado do produto, moderado significado do produto e alto significado do produto. Há uma diferença significativa entre as médias dos subgrupos ( $F(314$, $2)=126,946 ; p=0,000)$. Alto significado do produto obteve a maior avaliação na escala, demonstrando que quanto mais alto o significado do produto maior será a tendência de o consumidor realizar compras por impulso.

A aceitação da hipótese $\mathrm{H}_{3}$ corroborou o que muitos estudiosos já propuseram (Belk, 1988; Dittmar, Beattie \& Friese, 1995): que a compra por impulso está associada à relação existente entre o significado do produto e a autoimagem desejada no indivíduo. Quando o consumidor percebe a compatibilidade entre o objeto e a sua imagem, este acaba por engajar-se em comportamentos impulsivos de compra.

\subsection{Regressão Logística}

Segundo Hosmer e Lemeshow (1989), a técnica de regressão logística tornou-se um método padrão de análise de regressão para variáveis medidas de forma dicotômica. A técnica busca explicar ou predizer valores de uma variável em função de valores conhecidos de outras variáveis. A variável y é dicotômica. Neste trabalho, definiu-se operacionalmente para a variável y: $0=$ não compra por impulso e 1 = compra por impulso. As variáveis independentes foram utilizadas com os valores intervalares de 1 a 7.

Foi utilizado o método Enter. Nesse caso, conforme a Tabela 2, 192 consumidores compram por impulso e 125 não compram por impulso. Dessa forma, se o software prevê que todos os consumidores compram por impulso, essa previsão estará correta 192 vezes em 317 (isto é, 61\%, aproximadamente), caso contrário, se o software prevê que cada consumidor não compra por impulso, a previsão estará correta 125 vezes em 317 (39\%, aproximadamente). Diante do exposto, pode-se prever que todos os consumidores que compram por impulso resultam em um número maior de previsões corretas. Nesse caso, o percentual geral de acerto nas classificações seria de $60,6 \%$. Vale ressaltar que tal classificação está operando sem as variáveis independentes.

Tabela 2

Tabela de Classificação

\begin{tabular}{|c|c|c|c|c|}
\hline \multirow{3}{*}{\multicolumn{2}{|c|}{ Observed }} & \multicolumn{3}{|c|}{ Predicted } \\
\hline & & \multicolumn{2}{|c|}{ Compra por impulso } & \multirow{2}{*}{$\begin{array}{c}\text { Percentage } \\
\text { Correct }\end{array}$} \\
\hline & & $\begin{array}{l}\text { Não compra } \\
\text { por impulso }\end{array}$ & $\begin{array}{c}\text { Compra por } \\
\text { impulso }\end{array}$ & \\
\hline \multirow{2}{*}{ Compra por impulso } & Não compra por impulso & 0 & 125 & 0,0 \\
\hline & Compra por impulso & 0 & 192 & 100,0 \\
\hline \multicolumn{2}{|c|}{ Overall Percentage } & & & 60,6 \\
\hline
\end{tabular}

Fonte: Elaborado pelos autores.

A estatística Wald que é apresentada na Tabela 3, nesse primeiro momento, está avaliando apenas a significância da constante incluída no modelo. Este recurso será novamente utilizado para avaliar a significância dos coeficientes de cada variável independente. Sua finalidade é verificar se 
cada um deles é significativamente diferente de zero. Pode ser visto na Tabela 2 que o valor da constante é 0,429 .

Tabela 3

Variáveis na Equação

Fonte: Elaborado pelos autores.

\begin{tabular}{c|c|c|c|c|c|c|c}
\hline \multicolumn{2}{l|}{} & B & S.E. & Wald & Dz & Sig. & Exp(B) \\
\hline Step 0 & Constant & 0,429 & 0,115 & 13,946 & 1 & $\begin{array}{l}0,00 \\
0\end{array}$ & 1,536 \\
\hline
\end{tabular}

A Tabela 4 demonstra que 41,3\% (Cox \& Snell) das variações ocorridas no modelo são explicadas pelo conjunto de variáveis independentes (impulsividade, personalidade da marca e significado simbólico do produto). Dessa maneira, o modelo proposto é capaz de explicar cerca de $55,9 \%$ (Nagelkerke) das variações registradas na variável dependente.

Tabela 4

Sumário do Modelo

\begin{tabular}{c|c|c|c}
\hline Step & -2 Log likelihood & $\begin{array}{c}\text { Cox \& Snell R } \\
\text { Square }\end{array}$ & Nagelkerke R Square \\
\hline 1 & $256,476^{\mathrm{a}}$ & 0,413 & 0,559 \\
\hline
\end{tabular}

Fonte: Elaborado pelos autores.

Com o objetivo de testar a hipótese de que não há diferenças significativas entre os resultados preditos pelo modelo e os observados, foi utilizado um indicador denominado Teste Hosmer e Lemeshow. Para tanto, os casos foram divididos em dez grupos aproximadamente iguais e compararam-se os valores observados com os separados.

Tabela 5

Tabela de Contingência para o Teste de Hosmer e Lemeshow

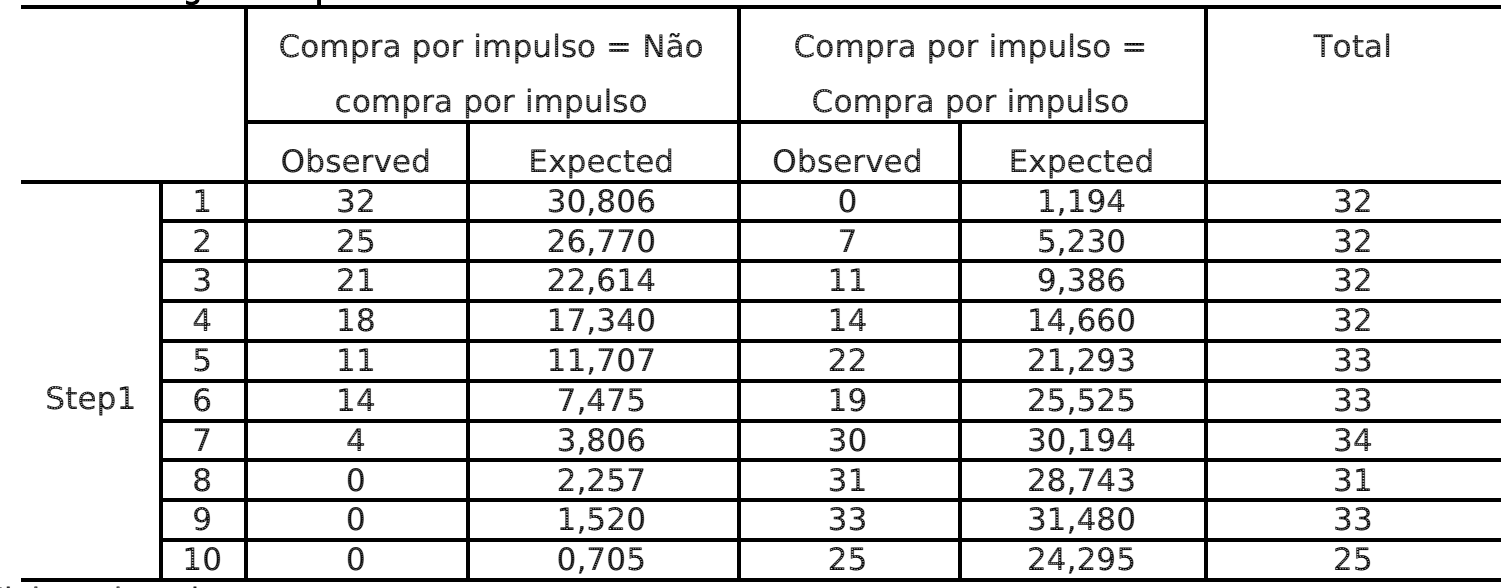

Fonte: Elaborado pelos autores.

Esse teste busca avaliar se há diferença significativa entre as frequências observadas e esperadas em cada faixa. Seguindo uma distribuição Qui-quadrado, o cálculo leva a uma estatística de 14,598 e um nível de Significância de 0,067 (ver Tabela 6). Isso indica que não há grande diferença entre as frequências previstas e observadas, o que é considerado bom, porque espera-se que estes valores sejam próximos.

Tabela 6

Teste de Hosmer e Lemeshow

\begin{tabular}{c|c|c|c}
\hline Step & Chi-square & DF & Sig. \\
\hline 1 & 14,598 & 8 & 0,067 \\
\hline
\end{tabular}

Fonte: Elaborado pelos autores.

A Tabela 7 mostra o quanto o modelo classifica corretamente os eventos. Assim, o percentual de acerto dos consumidores que não compram por impulso foi de $71,2 \%(=89 /(89+36))$ e os consumidores que compram por impulso $85,9 \%(165 /(165+27))$. Considerando a inclusão das variáveis, a classificação dos consumidores aumentou para $80,1 \%$. Embora se verifique uma redução no nível de acerto em relação à classificação dos consumidores na condição de comprar por impulso, 
já que antes estava em 100 e agora declinou para 85,9\%, no cálculo geral o modelo alcança melhor desempenho.

Tabela 7

Tabela de Classificação 2

\begin{tabular}{|c|c|c|c|c|c|}
\hline & \multirow{3}{*}{\multicolumn{2}{|c|}{ Observed }} & \multicolumn{3}{|c|}{ Predicted } \\
\hline & & & \multicolumn{2}{|c|}{ Compra por impulso } & \multirow{2}{*}{$\begin{array}{c}\text { Percentage } \\
\text { Correct }\end{array}$} \\
\hline & & & $\begin{array}{l}\text { Não compra } \\
\text { por impulso }\end{array}$ & $\begin{array}{c}\text { Compra por } \\
\text { impulso }\end{array}$ & \\
\hline \multirow{3}{*}{ Step 1} & \multirow{2}{*}{ Compra por impulso } & Não compra por impulso & 89 & 36 & 71,2 \\
\hline & & Compra por impulso & 27 & 165 & 85,9 \\
\hline & \multicolumn{2}{|c|}{ Overall Percentage } & & & 80,1 \\
\hline
\end{tabular}

Fonte: Elaborado pelos autores.

A Tabela 8 apresenta os resultados dos parâmetros estimados, que se mostraram significativos, uma vez que todos os valores de Significância foram inferiores ao nível de 5\%.

Tabela 8

Variáveis na Equação 2

\begin{tabular}{|c|c|c|c|c|c|c|c|c|c|}
\hline & \multirow[b]{2}{*}{ B } & \multirow[b]{2}{*}{ E. } & \multirow[b]{2}{*}{ Wald } & \multirow[b]{2}{*}{ Df } & \multirow[b]{2}{*}{ Sig. } & \multirow[b]{2}{*}{$\operatorname{Exp}(B)$} & \multicolumn{2}{|c|}{$95 \%$ C.I.for $\operatorname{EXP}(\mathrm{B})$} \\
\hline & & & & & & & & Lower & Upper \\
\hline \multirow{4}{*}{ Step 1} & Newlmpuls & 0,102 & 0,029 & 12,006 & 1 & 0,001 & 1,107 & 1,045 & 1,173 \\
\hline & NewSigProd & 0,100 & 0,026 & 14,383 & 1 & 0,000 & 1,105 & 1,049 & 1,163 \\
\hline & NewMarca & 0,035 & 0,016 & 4,773 & 1 & 0,029 & 1,036 & 1,004 & 1,069 \\
\hline & Constant & $-6,328$ & 818 & 59,841 & 1 & 0,000 & 0,002 & & \\
\hline
\end{tabular}

Fonte: Elaborado pelos autores.

Como se observa, a tabela sugere que todas as variáveis podem ser aproveitadas na composição do modelo, já que seus coeficientes não são nulos. Em outras palavras, pode-se afirmar que cada uma delas exerce efeito sobre a probabilidade de um consumidor comprar ou não por impulso, pelo menos a um nível de significância de 0,05.

\section{Conclusão}

Compreender em que medida e proporção os elementos que envolvem o comportamento de compra por impulso são os principais motivadores que levam inúmeros pesquisadores, como Rook e Hoch (1985), a aprofundarem suas pesquisas sobre o tema. Apesar de a última década ter proporcionado uma maior compreensão sobre o fenômeno, a compra por impulso ainda necessita de um entendimento mais aprofundado.

O presente trabalho buscou diminuir as lacunas existentes sobre o comportamento de compra por impulso, a partir da formulação de um estudo que explicasse o comportamento de compra por impulso levando em consideração aspectos que, até então, não foram analisados conjuntamente, como a impulsividade do indivíduo, personalidade da marca e significado do produto.

De acordo com o objetivo deste artigo de analisar a influência dos construtos impulsividade, significado do produto e personalidade da marca na compra por impulso, foram considerados os seguintes objetivos específicos: (1) analisar o impacto da impulsividade do indivíduo na ocorrência de compras por impulso; (2) avaliar a importância da personalidade da marca na escolha de um produto em relação a uma possível compra por impulso; e (3) analisar a influência que o significado do produto exerce sobre a compra por impulso.

Fazendo uma avaliação do primeiro objetivo específico, foi possível perceber, por meio dos resultados da pesquisa, que os indivíduos mais impulsivos tendem, com maior frequência, fazer compras por impulsos, ou seja, tais indivíduos apresentaram dificuldade em controlar seus impulsos de compra. Esse resultado converge com a teoria, que afirma que indivíduos impulsivos enfrentam dificuldade em controlar suas reações. Por não possuir objetivos e nem regras em suas atividades de consumo, apresentam maior tendência a comprar impulsivamente (Baumeister, 2002). 
O segundo objetivo específico foi avaliar a importância da personalidade da marca na escolha de um produto em relação a uma possível compra por impulso, por meio dos resultados obtidos com a pesquisa em campo. Percebeu-se que aos produtos adquiridos de forma impulsiva, eram atribuídas personalidades, e quanto mais essa personalidade da marca conseguia identificar-se com o consumidor e o seu estilo de vida, mais os produtos estariam propensos a serem adquiridos impulsivamente. Möller e Herm (2013) já afirmavam em seus estudos que os consumidores tendem a escolher a marca que melhor se adapte à sua personalidade. Desse modo, a personalidade da marca influencia a escolha de um produto em detrimento de outro. Consumir determinado produto é o meio pelo qual o consumidor pode comunicar o tipo de pessoa que é ou que deseja ser.

Por fim, analisando o último objetivo específico, que propôs analisar a influência que o significado do produto exerce sobre a compra por impulso, pode-se observar, por meio dos resultados da pesquisa, que os produtos adquiridos de forma impulsiva são aqueles compatíveis com a imagem do consumidor, que refletem quem eles são. Dessa forma, demonstra-se que a compra por impulso é influenciada pela relação existente entre o significado do produto e a imagem do indivíduo. O simbolismo dos produtos é uma parte importante da decisão de comprá-lo, até mais do que as características funcionais. Como afirmou Belk (1988), os comportamentos impulsivos de compra são influenciados pela compatibilidade entre o objeto e a imagem do consumidor.

Portanto, conclui-se que a compra por impulso recebe influências significativas da impulsividade do indivíduo, da personalidade da marca e do significado do produto, deixando evidente que o comportamento de compra por impulso recebe influência dos aspectos simbólicos dos produtos e das marcas.

Outras contribuições podem ser inferidas quanto ao local onde foram aplicados os questionários e o momento da coleta dos dados. Os questionários foram aplicados em um shopping center, ambiente projetado para incentivar a impulsividade (Padilha, 2006; Underhill, 2009), identificado como fator determinante para a ocorrência de compras por impulso. Os consumidores foram abordados no momento em que saíam das lojas, quando tinham acabado de vivenciar uma experiência de compra. Isto pode ter ajudado em uma avaliação mais concisa a respeito do comportamento de compra por impulso.

O presente estudo contribui para o meio acadêmico porque foi realizado em condições reais, possibilitando a avaliação de situações empíricas. O estudo apresentou-se como inédito, pois buscou analisar a influência conjunta dos construtos impulsividade, personalidade da marca e significado dos produtos na ocorrência de compras por impulso, visto que a maioria dos estudos realizados nesta área busca analisar as influências ambientais.

Outra contribuição refere-se às variáveis criadas e acrescentadas na escala significado do produto. Tais variáveis passaram pela análise de confiabilidade interna, por meio da apuração do coeficiente Alfa de Cronbach e apresentou resultado satisfatório. Dessa forma não foram excluídas, podendo ser usadas para futuros estudos na área.

O modelo apresentou resultados relevantes em nível de significância estatística e um avanço na literatura a respeito do fenômeno da compra por impulso. Como a competição tem se intensificado, é importante que os profissionais compreendam a importância da impulsividade, personalidade da marca e significado do produto no comportamento de compra. O presente estudo permitiu um melhor entendimento desse fenômeno, que tem recebido pouca atenção por parte do meio empresarial.

Ao aproximar o modelo acadêmico à realidade empresarial, amplia-se a base para a tomada de decisões estratégicas, o que representa para as organizações um diferencial competitivo. Apesar do rigor científico, o estudo está sujeito a limitações como: (a) para entender melhor as razões que levam o consumidor a comprar por impulso seria importante utilizar uma pesquisa de caráter qualitativo, já que o presente estudo utilizou apenas técnicas quantitativas; (b) a aplicação de questionários de pesquisa pode levar a ocorrência da chamada Social Desirable Responding (SDR) quando o consumidor tende a responder os questionários com respostas socialmente desejáveis, que muitas vezes não refletem seu comportamento de compra; (c) ao se trabalhar com indivíduos deve-se levar em consideração que os mesmos possuem dificuldade de fazer uma autoavaliação do seu comportamento de compra, em níveis diferenciados.

Este trabalho não se propõe a ser conclusivo, assinalando que futuros estudos são necessários para melhor compreender o fenômeno compra por impulso. Para futuros estudos sugere-se: (a) realizar pesquisa com objetivos semelhantes, mas que utilize outros métodos tanto de natureza quantitativa (por exemplo, os estudos experimentais) quanto qualitativa; (b) levar em 
consideração os estados emocionais dos consumidores; (c) analisar o arrependimento pós-compra por impulso.

\section{Referências}

Aaker, D. \& Biel, A. (1993). Brand equity and advertising: An overview. In: Aaker, D. \& Biel, A. Brand equity and advertising. New Jersey: Lawrence Erlbaum Associates.

Aaker, J. (1997). Dimensions of brand personality. Journal of Marketing Research,34(3) 347-356.

Aaker, J. L., Benet-Martínez, V. \& Garolera, J. (2001). Consumption symbols as carriers of culture: A study of Japanese and Spanish brand personality constructs. Journal of Personality and Social Psychology, 81(3) 492-508.

Allen, M. W. (2000). The Attribute-mediation and product meaning approaches to the influences of human values on consumer choices. In: Columbus, F. (Ed.). Advances in Psychology Research. Huntington: Nova Science Publishers, p. 31-76.

Amos, C., Holmes, G \& Keneson, W. (2014). A meta analysis of consumer impulse buying. Journal of Retailing and Consumer Services, 21(2) 86-97.

Arnould, E., Price, L. \& Zinkhan, G. (2004). Consumers. 2. Ed. Boston: McGraw-Hill.

Babin, B., Darden, W. R. \& Griffin, M. (1994). Work and/or fun: Measuring hedonic and utilitarian shopping value. Journal of Consumer Research, 20(1) 644-656.

Baudrillard, J. (2005). A Sociedade de Consumo. Lisboa: Edições 70.

Baumeister, R. F. (2002). Yielding to temptation: Self-control failures, impulsive purchasing, and consumer behavior. Journal of Consumer Research, 28(4) 670-676.

Beatty, S. \& Ferrel, E. (1998). Impulse buying: modeling its precursors. Journal of Retailing, 74(2) 169-191.

Belk, R. W. (1988). Possessions and the extended self. Journal of Consumer Research, 15(2) 139-168.

Brunner, C. B., Ullrich, S., Jungen, P. \& Esch, F. R. (2016). Impact of symbolic product design of brand evaluations. Journal of Product \& Brand Management, 25(30) 307-320.

Caprara, G., Barbaranelli, C. \& Guido, G. (1998). Personality as metaphor: Extension of the psycholexical hypothesis and the five fator model to brand and product personality description. Europe Advances in Consumer Research, 3(1) 61-69.

Costa, F. C. X. (2002). Influências ambientais e o comportamento de compra por impulso: um estudo em lojas físicas e virtuais. Tese de Doutorado, Departamento de Administração, Universidade de São Paulo, (USP), São Paulo, Brasil.

Costa, M. F. \& Farias, S. A. (2016). Efeitos da música ao vivo e mecanizada em ambientes de varejo supermercadista. Revista de Administração Contemporânea-RAC, 20(2) 154-174.

Darrat, A. A., Darrat, M. A. \& Amyx. D. (2016). How impulse buying influences compulsive buying: The central role of consumer anxiety and escapism. Journal of Retailing and Consumer Services, 31(2) 103-108.

Das, G. (2014). Impacts of retail brand personality and selfcongruity on store loyalty: The moderating role of gender. Journal of Retailing and Consumer Services, 21(2) 130-138.

Dean, D., Arroyo-Gamez, R., Punjaisri, K. \& Pich, C. (2016). Internal brand co-creation: The experiential brand meaning cycle in higher education. Journal of Business Research, 69(8) 30413048.

Dholakia, U. (2000). Temptation and resistance: An integrated model of consumption impulse formation and enactment. Psychology \& Marketing, 17(1) 955-982.

Dittmar, H., Beattie, J. \& Friese, S. (1995). Gender identity and symbols: Objects and decisions considerations in impulse purchases. Journal of Economic Psychology, 16(1) 491-511.

Douglas, M. \& Isherwood, B. (2009). O mundo dos bens: por uma antropologia do consumo. Rio de Janeiro: Ed UFRJ.

Eisend, M. \& Stokburger-Sauer, N. E. (2013). Brand personality: A meta-analytic review of antecedents and consequences. Marketing Letters, 23(3) 205-216. 
Faber, R. J. (1992). Money changes everything: Compulsive buying from a biopsychosocial perspective. American Behavioral Scientist, 35(July) 809-819.

Ferguson, G., Lau, K. C. \& Phau, I. (2016). Brand personality as a direct cause of brand extension success: Does self-monitoring matter? Journal of Consumer Marketing, 33(5) 343-353.

Grohmann, B., Giese, J. L. \& Parkman, I. D. (2013). Using type font characteristics to communicate brand personality of new brands. Journal of Brand Management, 20(5) 389-403.

Hair, Jr.; J. F., Babin, B., Money, H. A. \& Samoul, P. (2005). Fundamentos de métodos de pesquisa em administração. Porto Alegre: Bookman.

Hemsley-Brown, J., Melewar, T., Nguyen, B. \& Wilson, E. (2016). Exploring brand identity, meaning, image, and reputation (BIMIR) in higher education: A special section. fournal of Business Research, 69(8) 3019-3022.

Hoch, S. \& Loewenstein, G. (1991). Time-inconsistent preferences and consumer self-control. Journal of Consumer Research, 17(4) 492-507.

Hosmer, D. W. \& Lemeshow, S. (1989). Applied logistic regression. Wiley, New York.

Huang, L. T. (2016). Flow and social capital theory in online impulse buying fournal of Business Research, 69(6) 2277-2283.

Kapferer, J. (2004). Marcas à prova de prática: Aprendendo com os erros. Porto Alegre: Bookman.

Levy, S. J. (1959). Symbols for sales. Harvard Business Review, 37(4) 117-124.

Malhotra, N. K. (2006). Pesquisa em marketing: Uma orientação aplicada. Porto Alegre: Bookman.

McCracken, G. (2003). Cultura \& consumo: novas abordagens ao caráter simbólico dos bens e das atividades de consumo. Coleção Cultura e Consumo, Rio de Janeiro: Mauad.

Möller, J. \& Herm, S. (2013). Shaping Retail Brand Personality Perceptions by Bodily Experiences. Journal of Retailing, 89(4) 438-446.

Muniz, K. M. \& Marchetti, R. Z. (2005). Dimensões da personalidade de marca: Análise da adequação da escala de Aaker (1997) ao contexto brasileiro. Anais do EnAnpad..., Rio de janeiro.

Nepomuceno, M. V. \& Torres, C. V. (2005). Validação da escala de julgamento e significado do produto. Estudos de Psicologia, 10(1) 421-430.

Nohara, J. J., Acevedo, C. R. \& Nogueira Neto, L. G. (2015). Consumo compulsivo e valores materialistas. Business and Management Review, 5(1) 700-711.

O'Guinn, T. C., \& Faber, R. J. (1989). Compulsive buying: A phenomenological exploration. Journal of Consumer Research, 16(2) 147-157.

Ozer, L\& Gultekin, B. (2015). Pre- and post-purchase stage in impulse buying: The role of mood and satisfaction. Journal of Retailing and Consumer Services, 22(1) 71-76.

Padilha, V. (2006). Shopping Center. A catedral das mercadorias. São Paulo: Boitempo editorial.

Richins, M. L. (1994). Valuing things: The public and private meanings of possessions. Journal of Consumer Research, 21(1) 504-521.

Ranfagni, S., Camiciottoli, B. C. \& Faraoni, M. (2016). How to measure alignment in perceptions of brand personality within online communities: interdisciplinary insights. Journal of Interactive Marketing, 35(August) 70-85.

Rook, D. (1987). The buying impulse. Journal of Consumer Research, 14(1) 189-199.

Rook, D. W. \& Hoch, S. J. (1985). Consuming impulses. Advances in Consumer Research,12(1) 23-27.

Sampieri, R. H., Collado, C. F. \& Lucio, P. B. (2006). Metodologia de pesquisa. 3 ed. São Paulo: McGraw-Hill.

Santarelli, C. (2003). A moda tribal e seus aspectos comunicativos. Revista Brasileira de Marketing, 2(1) 95-104.

Slater, D. (2001). Cultura do consumo e modernidade. Rio de Janeiro: Nobel.

Sundar, A. \& Noseworthy, T. J. (2016). Too exciting to fail, too sincere to succeed: The effects of brand personality on sensory disconfirmation. Journal of Consumer Research, 43(1) 44-67. 
Supphellen, M. \& Gronhaug, K. (2003). Building foreign brand personalities in Russia: The moderating effect of consumer ethnocentrism. International journal of Advertising, 22(1) 203-226.

Tamayo, A. (1981). EFA: Escala fatorial de autoconceito. Arquivos Brasileiros de Psicologia, 33(4), 87102.

Tegglen, E. (1979). A sociedade de consumo. Rio de Janeiro: Salvat Editora do Brasil.

Thaler, R. (1985). Mental accounting and consumer choice. Marketing Science, 4(2) 199-214.

Underhill, P. (2009). Vamos às Compras: A ciência do consumo nos mercados globais. 1 ed. Rio de Janeiro: Campus.

Youn, S. (2000). The dimensional structure of consumer buying impulsivity: measurement and validation. Tese de Doutorado, Departamento de Administração, University of Minnesota, Minneapolis, USA.

Youn, S. \& Faber, R. (2000). Impulse buying: Its relation to personality traits and cues. Advances in Consumer Research, 27(1) 179-185.

Xiang, L., Zheng, X., Lee, M. \& Zhao, D. (2016). Exploring consumers' impulse buying behavior on social commerce platform: The role of parasocial interaction. International journal of Information Management, 36(3) 333-347. 